\title{
Fat and Fibrin Glue: Quo Vadis?
}

\author{
Juan F. VILLALONGA ${ }^{1}$, Domenico SOLARI ${ }^{2}$, Giulia GUIZZARDI ${ }^{2}$, Maria Rosaria SCALA², Alvaro CAMPERO ${ }^{1,3}$ \\ 'Universidad Nacional de Tucumán, Facultad de Medicina, LINT, Tucumán, Argentina \\ ${ }^{2}$ Università degli Studi di Napoli Federico II, Reproductive and Odontostomatological Sciences, Department of Neurosciences, Division of \\ Neurosurgery, Naples, Italy \\ ${ }^{3}$ Hospital Padilla, Servicio de Neurocirugía,Tucumán, Argentina
}

Corresponding author: Juan F. VILLALONGA jfvillalonga@gmail.com

\section{ABSTRACT}

AIM: To analyze the effectiveness of fat and fibrin glue to prevent postoperative cerebrospinal fluid (CSF) leak in pituitary surgery.

MATERIAL and METHODS: Two hundred and eleven patients affected by pituitary adenoma entered this study. Patients that underwent a microscopic transsphenoidal approach between January 2013 and April 2019 were included. All the patients that developed intraoperative CSF leak were treated with fat and fibrin glue. The presence or absence of postoperative CSF leak was considered as a parameter to test the effectiveness of the intraoperative reconstruction technique used.

RESULTS: Postoperative CSF leak was observed in 5 patients (2.4\%). Among patients with an intraoperative low- grade CSF leak (1 or 2), 97.9\% did not develop a postoperative CSF leak. In contrast, those who presented an intraoperative CSF leak of grade 3 , had a worse prognosis.

CONCLUSION: Fat and fibrin glue is currently an effective method in the treatment of low-grade intraoperative CSF leak. In case of intraoperative CSF leak of grade 3, it should be used combined with the nasoseptal flap technique to obtain a safer reconstruction.

KEYWORDS: Cerebrospinal fluid leakage, Reconstructive phase, Pituitary surgery, Skull base

ABBREVIATIONS: CSF: Cerebro-spinal fluid, NSF: Naso-septal flap, EEA: Endoscopic endonasal approach, MRI: Magnetic resonance imaging

\section{INTRODUCTION}

$\mathrm{P}$ ituitary adenomas are usually benign lesions and their prevalence is increasing $(18,41)$. Apart from prolactinomas, surgery represents the first-line treatment (37).

The most feared complication of this surgery is the postoperative cerebrospinal fluid (CSF) leak (9). The introduction of nasoseptal flap (NSF) (23), in the reconstructive phase of this surgery, determined a remarkable decrease of postoperative CSF leak rates (29). However, this successful technique was designed for the endoscopic approach (23). According to this, in all the articles that reported a favorable experience with the NSF, the endoscopic-assisted technique was performed $(22,34,43)$.

Up to date, there are few conditions where the nasoseptal flap (NSF) is not considered as a valid option in the reconstructive phase: 1) when the neurosurgeon does not use an endoscopic technique or 2) when the neurosurgeon uses an endoscopic technique, but there is no genuine indication for the mentioned flap. Therefore, the young skull base neurosurgeon is challenged to master other techniques (other than NSF) for the reconstructive phase, which should be chosen based on the existing shreds of evidence regarding their efficacy. Our team decided to study a reconstruction technique that has been used for a long time: crural fat and fibrin glue.
Juan F. VILLALONGA (1) : 0000-0002-1544-6334

Domenico SOLARI

Giulia GUIZZARDI
Maria Rosaria SCALA (1) : 0000-0003-2318-2866

Alvaro CAMPERO (1) : 0000-0001-5184-5052 
This study aims to analyze the effectiveness of fat and fibrin glue to prevent postoperative CSF leak in pituitary surgery.

\section{n MATERIAL and METHODS}

Data were collected retrospectively and patients operated through a microscopic transsphenoidal approach between January 2013 and April 2019 were included. The senior author treated all patients. The ones operated through a transcranial approach and/or with history of previous pituitary adenoma surgeries or other types of sellar lesions were excluded.

The intraoperative videos of the patients included in our study were carefully reviewed to identify the presence of intraoperative CSF leak. Then, we stratified the patients according to their intraoperative CSF leak grade.

\section{Surgical Technique}

All the patients were treated by the same neurosurgeon (AC). The semi-sitting position was used, taking into account the concept of the spheno-seal point $(2,3)$. A microscopic assisted endonasal trans-sphenoidal approach was performed (6). During the nasal phase, nasal structures were preserved.

After detecting the intraoperative CSF leak, crural fat and fibrin glue (Beriplast ${ }^{\circledR} \mathrm{P}$ Combi set, CSL Behring, Montevideo, Uruguay) were placed.
The crural fat graft was collected using sterile dedicated instruments' set and was positioned in the space generated by the durotomy. The edges of the fat block were placed perfectly in-lay. Afterwards, the interface between the dura mater and the fat was sealed with fibrin glue. Finally, it was asked to the anesthesiologist to induce Valsalva's manoeuver to assess the efficacy of reconstruction.

No other hemostatic agents were used. During the reconstructive phase, the nasoseptal flap was not harvested. Lumbar drainage was not positioned. In the postoperative period, the patients stayed in bed for 48 hours with the head at 30 degrees. Pre and postoperative MRIs with detailed intraoperative images of six patients are shown in the Figures (Figure 1-6).

\section{Classification of the intraoperative CSF leak}

Esposito et al. published a useful CSF leak grading system during the intraoperative stage (19). We can synthesize it as follows: Grade 0, no leak observed; Grade 1, small leak, confirmed by Valsalva manoeuver, without obvious diaphragmatic defect; Grade 2, moderate leak with obvious diaphragmatic defect; or Grade 3, large diaphragmatic defect.

\section{RESULTS}

Of the 211 patients included in this study, 51 presented intra-
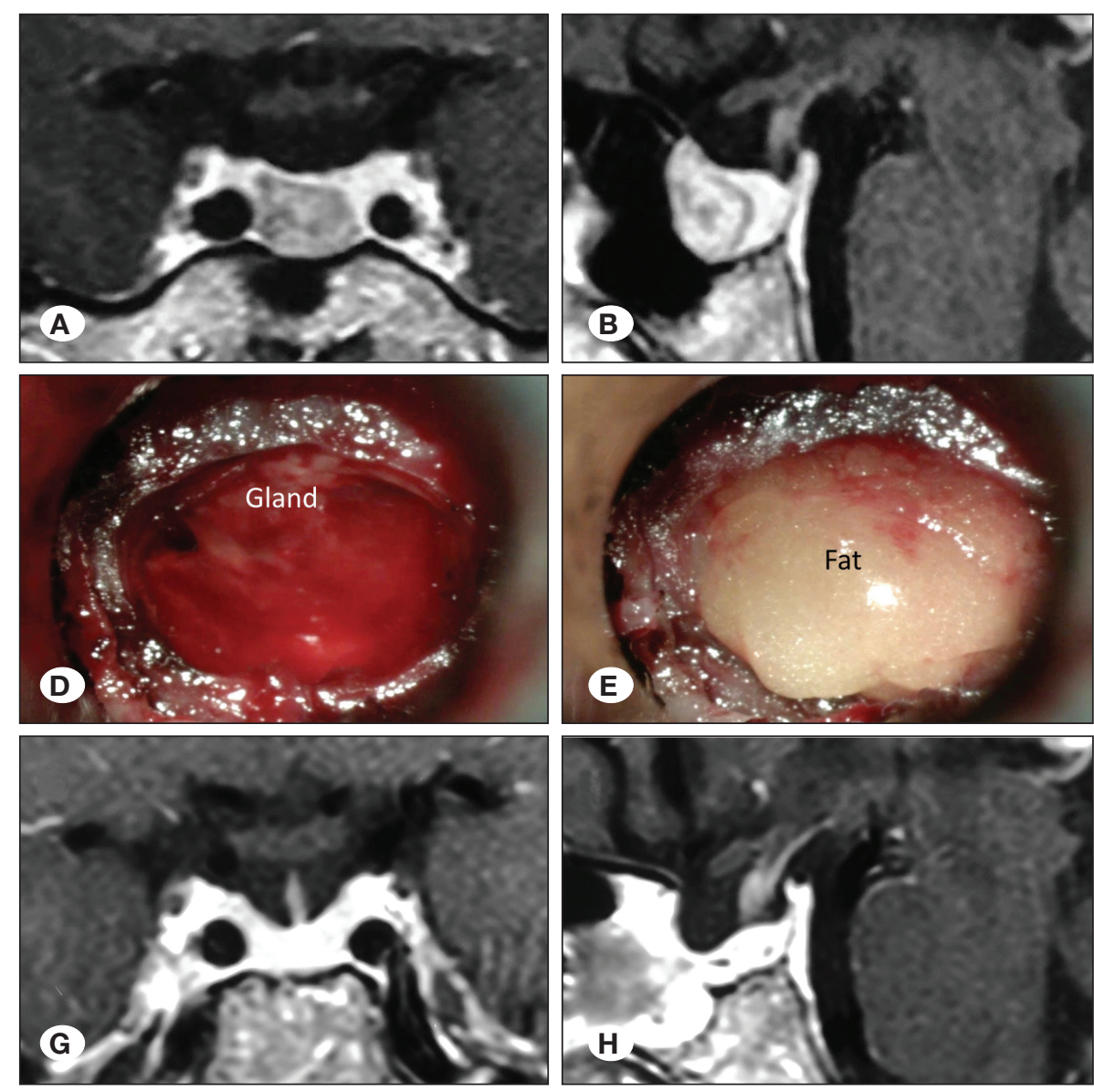
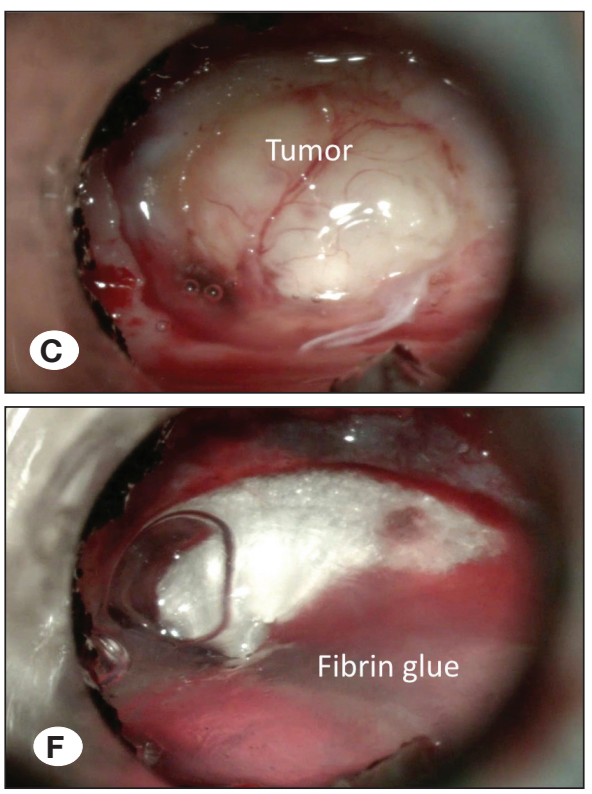

Figure 1: Images of a 39-years-old female patient with acromegaly.

A, B) Preoperative MRI that shows a mixed sellar barrier;

C-F) intraoperative findings;

G, H) postoperative MRI. 

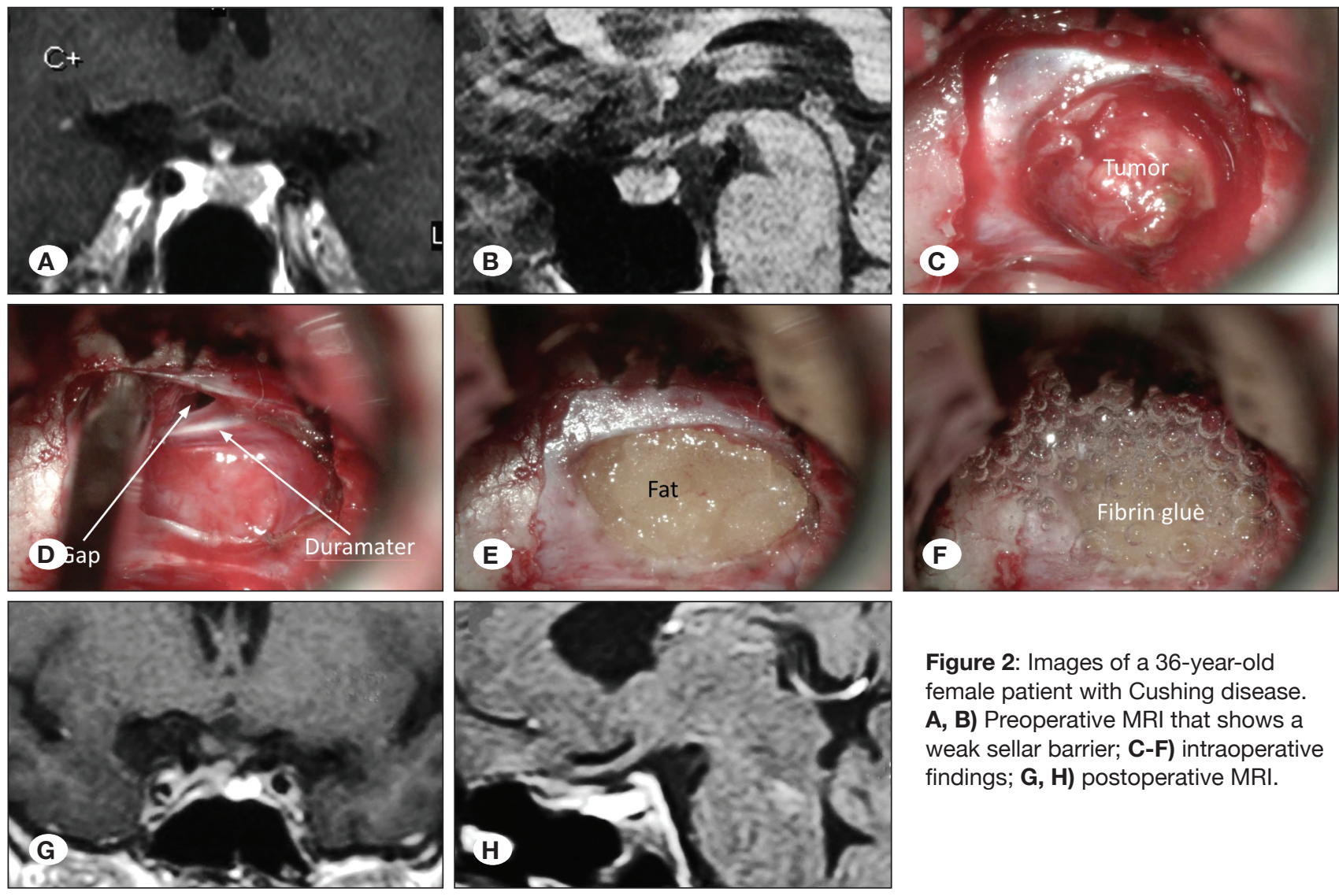

Figure 2: Images of a 36-year-old

female patient with Cushing disease.

A, B) Preoperative MRI that shows a weak sellar barrier; C-F) intraoperative findings; G, H) postoperative MRI.
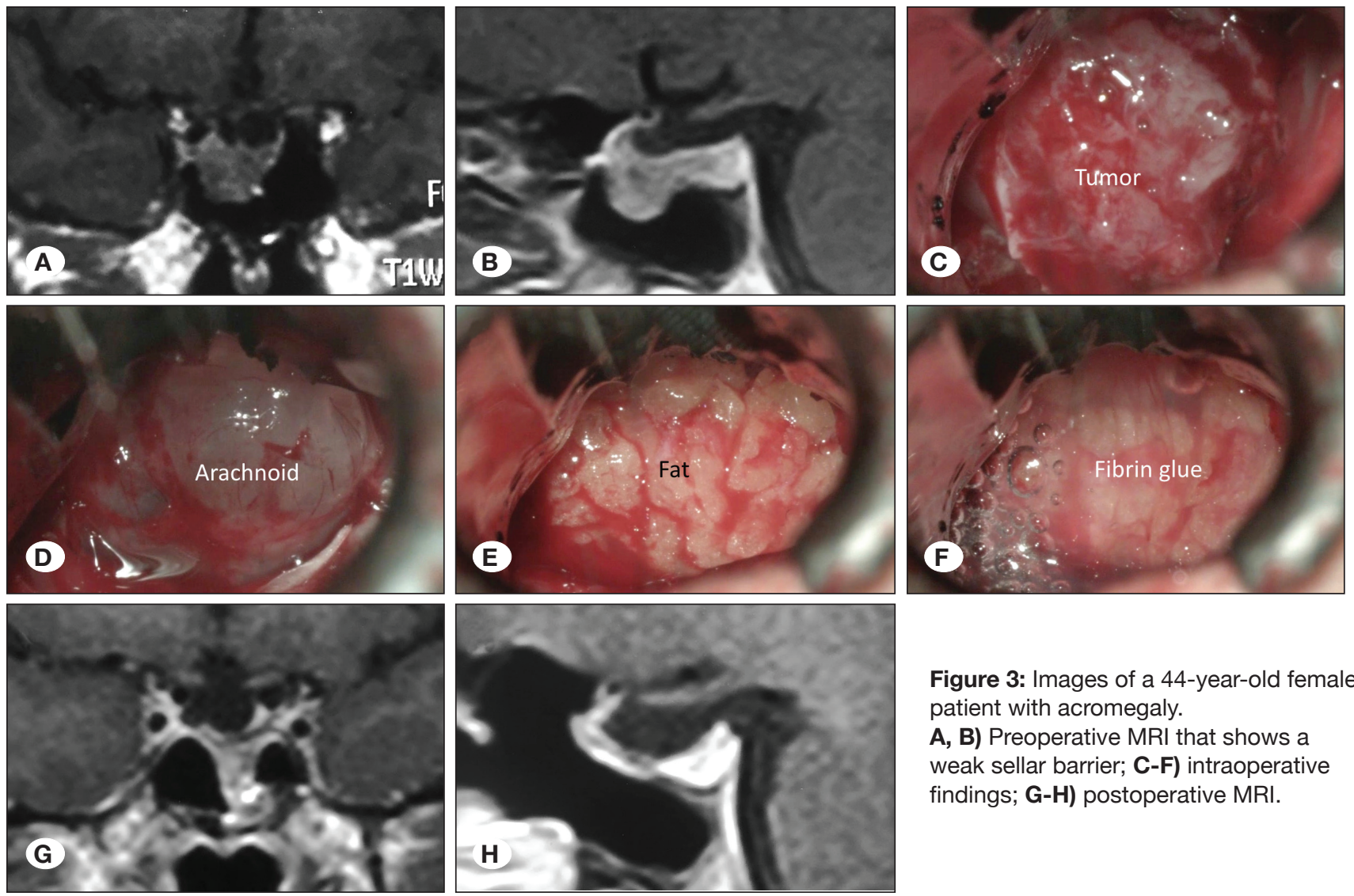

Figure 3: Images of a 44-year-old female patient with acromegaly.

A, B) Preoperative MRI that shows a weak sellar barrier; C-F) intraoperative findings; G-H) postoperative MRI. 

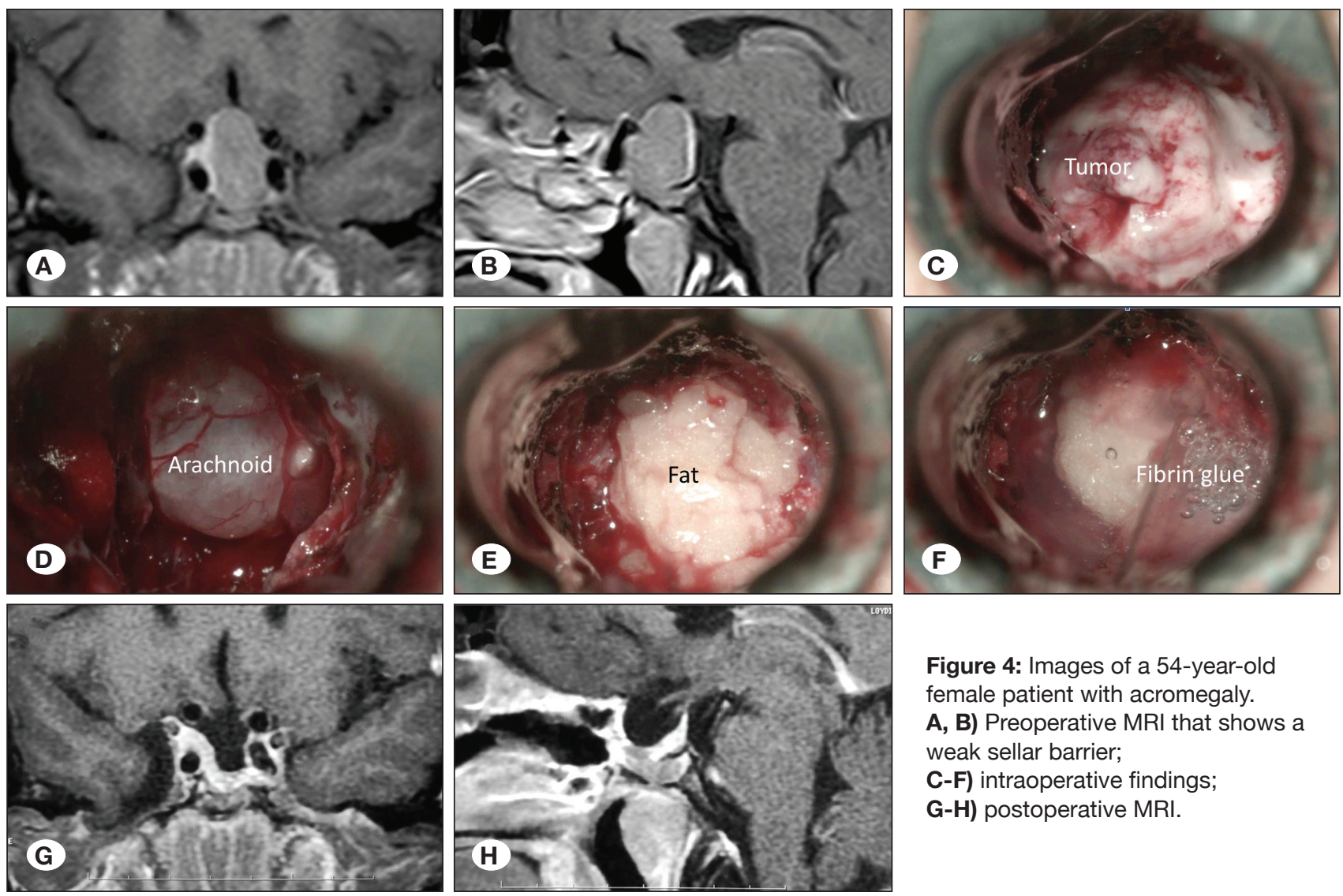

Figure 4: Images of a 54-year-old female patient with acromegaly.

A, B) Preoperative MRI that shows a weak sellar barrier;

C-F) intraoperative findings;

G-H) postoperative MRI.
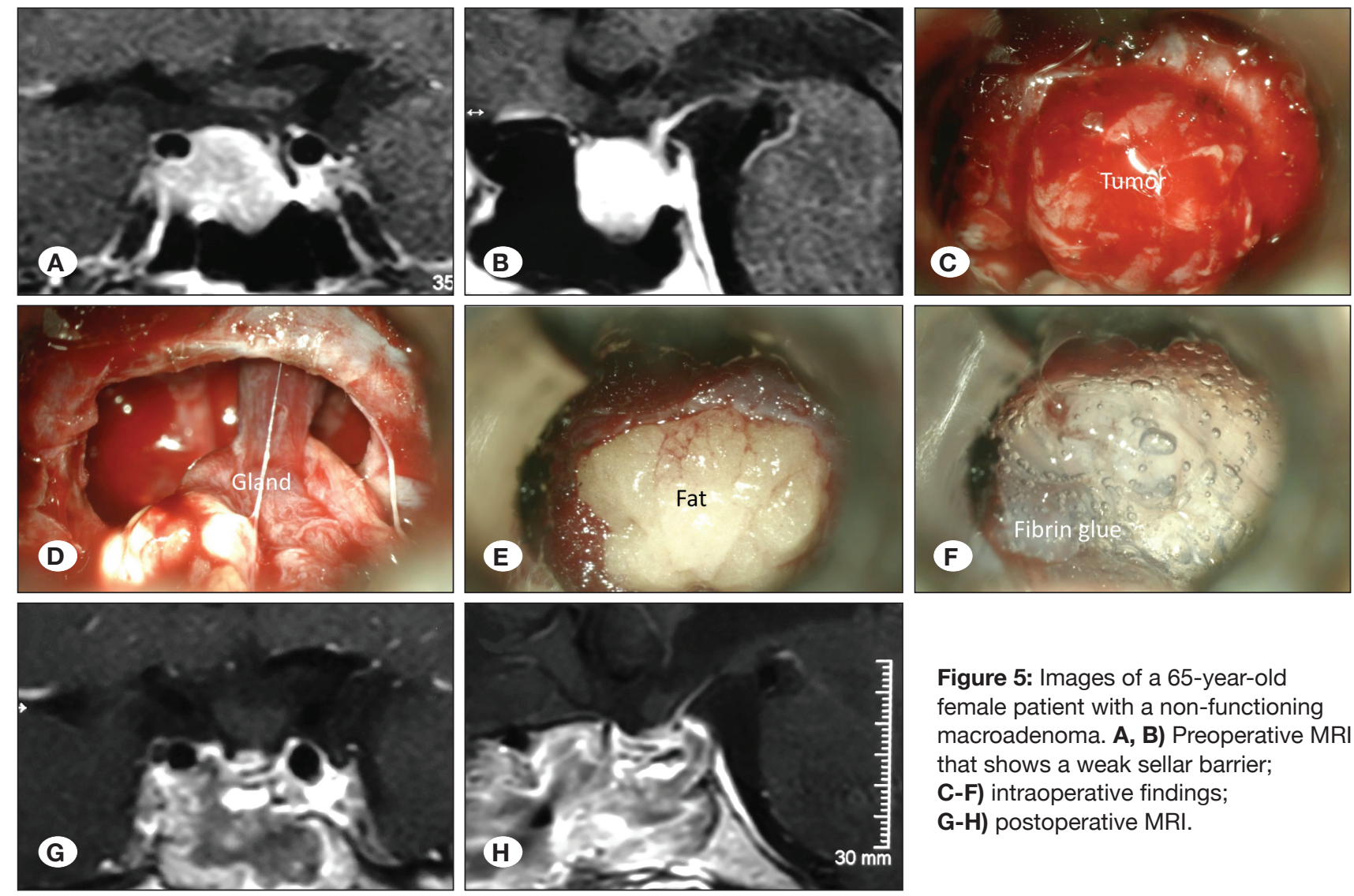

Figure 5: Images of a 65-year-old female patient with a non-functioning macroadenoma. A, B) Preoperative MRI that shows a weak sellar barrier; C-F) intraoperative findings; G-H) postoperative MRI. 

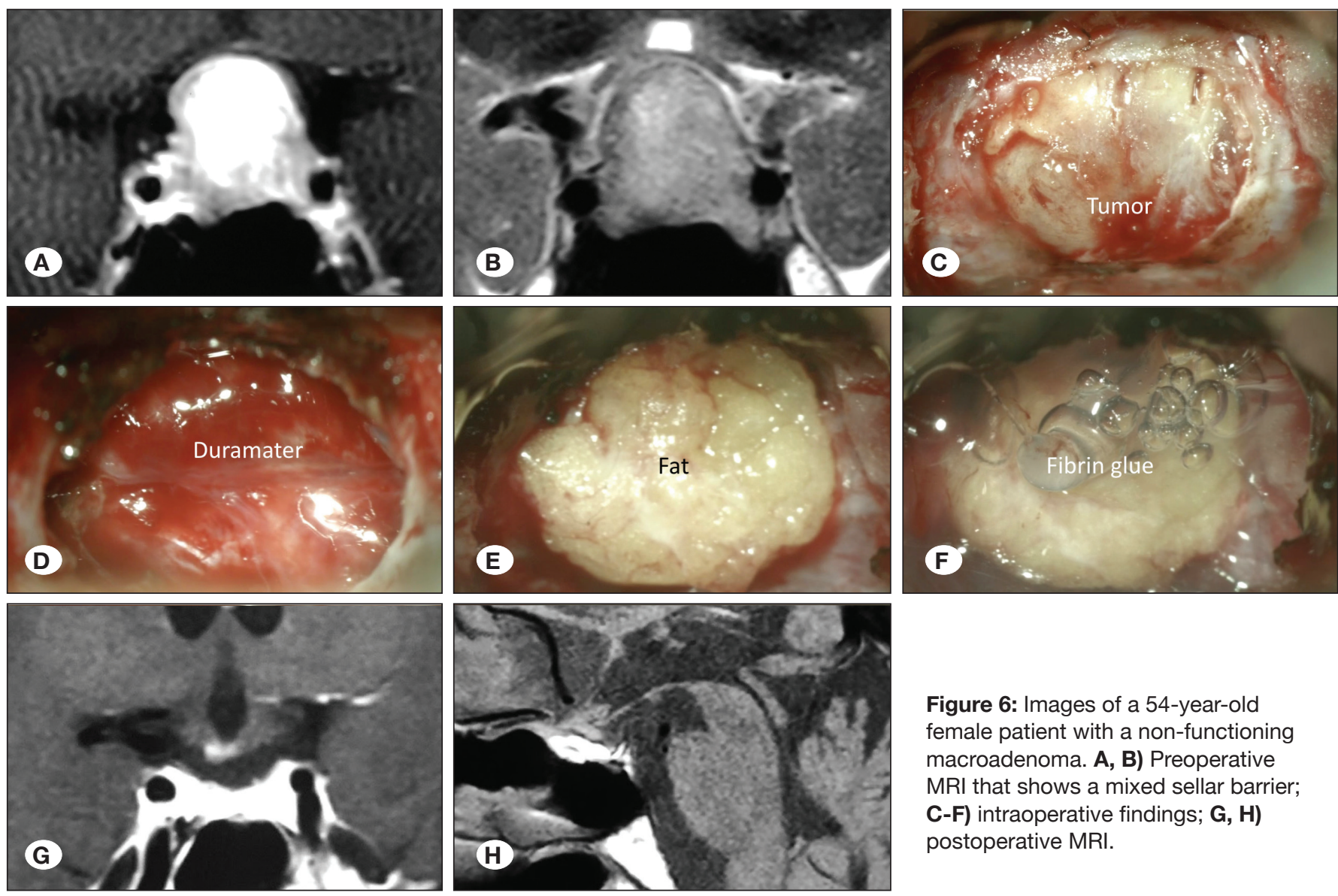

Figure 6: Images of a 54-year-old female patient with a non-functioning macroadenoma. A, B) Preoperative MRI that shows a mixed sellar barrier; C-F) intraoperative findings; $\mathbf{G}, \mathbf{H}$ ) postoperative MRI.

operative CSF leak and 5 patients developed postoperative CSF leak (Table I).

Intraoperative CSF leak rate was $24.2 \%(n=51)$. All of these patients were treated with autologous fat and fibrin glue without using flaps.

The overall postoperative CSF leak rate was $2.4 \%(n=5)$. The rate of postoperative CSF leak in patients with evidence of intraoperative CSF leak was $9.8 \%(n=5)$. In these patients, lumbar drainage was positioned and revision surgery was performed: the first reconstruction was removed and a second fat graft, collected from the same crural site, was placed inside the osteodural defect and sealed with an external layer of fibrin glue. No further complications were noted.

The intraoperative CSF leak grade distribution, according to the mentioned classification, was: $75.8 \%$ with grade 0 $(n=160), 7.1 \%$ with grade $1(n=15), 15.2 \%$ with grade $2(n=32)$, and $1.9 \%$ with grade $3(n=4)$.

Table I shows the number of patients with intraoperative CSF leak according to their grades and evidence of postoperative CSF leak. Among the patients with intraoperative CSF leak of grade $1(n=15)$, no cases of postoperative CSF leak were observed. Patients with evidence of intraoperative CSF leak of grade $2(n=32)$ presented postoperative CSF leak in 1 case (3.1\%).
Table I: Number of Patients with Postoperative CSF Fistula according to Their Grade of Intraoperative CSF Leak

\begin{tabular}{lcc}
\hline $\begin{array}{l}\text { Intraoperative CSF } \\
\text { Leak Grade }\end{array}$ & $\begin{array}{c}\text { Number of } \\
\text { Patients }\end{array}$ & $\begin{array}{c}\text { Postoperative } \\
\text { CSF fistula }\end{array}$ \\
\hline 0 & 160 & 0 \\
\hline 1 & 15 & 0 \\
\hline 2 & 32 & 1 \\
\hline 3 & 4 & 4 \\
\hline
\end{tabular}

All patients with intraoperative CSF leak of grade $3(n=4)$ presented postoperative CSF leak (100\%). Within the patients with postoperative CSF leak $(n=5), 80 \%(n=4)$ were classified with an intraoperative CSF leak of grade 3 and $20 \%(n=1)$ a grade 2 .

Among all the patients included in the series $(n=211), 97.6 \%$ $(n=206)$ did not develop postoperative CSF leak.

During the early postoperative period one case of crural subcutaneous hematoma $(n=1)$ was recorded as the only complication of the fat donor site. No crural wound infections were detected. 


\section{DISCUSSION}

\section{Intra and Postoperative CSF Leak Rates}

Several authors report global rates of postoperative CSF leak ranging from $3-5 \%$. Currently, this rate is similar for both microscopic and endoscopic techniques (30).

In the present study, using fat and fibrin glue as the only antiCSF leak method, the overall CSF leak rate was $2.4 \%$. The data and the results of the most recent published papers regarding sellar floor reconstruction techniques were analyzed. Our findings are aligned with the data previously reported (Table II) $(1,4,5,12-15,17,20,21,24-26,32,35,39,42)$.

Intraoperative CSF leak rates depend on several factors: the type of sellar barrier $(7,40)$, invasion of the third ventricle (19), BMI (20), and the surgeon's learning curve (21).

Strickland et al. reported that among their patients, $37.4 \%$ developed an intraoperative CSF leak (38). In our series, intraoperative CSF leak rate was $24 \%(n=51)$.

To calculate the overall CSF leak rate, the entire series of patients (with or without intraoperative CSF leak) was taken into account. However, the authors believe the effectiveness of an anti-CSF leak method should not be quantified on the overall postoperative CSF leak rate. For this reason, to determine the effectiveness of fat and fibrin glue as an antiCSF leak method, we included, in our analysis, just the patients with evidence of intraoperative CSF leak.

Consequentially, it is not possible to affirm that the effectiveness of the reconstruction technique used was represented by the overall percentage of patients without postoperative CSF leak $97.6 \%(n=206)$ because it would be conceptually wrong. The fat and fibrin glue method's effectiveness should not be estimated on the overall rate of postoperative CSF leak of $2.4 \%(n=5)$; in fact, this data has been calculated considering all the patients in the series $(n=211)$. The evaluation of the fat and fibrin glue reconstruction method's effectiveness should be based on the postoperative rate $(9.8 \%, n=5)$ of CSF leak in patients who presented intraoperative CSF leak $(n=51)$. Accordingly, it is represented by the rate of patients with intraoperative CSF leak who did not develop postoperative CSF leak $(90.2 \%, \mathrm{n}=46)$.

Comparing the success of the several anti-CSF leak methods reported in literature is not easy; according to that, as discussed in the previous section, the results generally show postoperative CSF leak rates, without specifying how many patients showed intraoperative CSF leak. Indeed, it is useful to distinguish, in the previous literature, intraoperative and postoperative CSF leaks rates (7).

Table II: Intra and Postoperative CSF Leak Rates Reported in the Previous Literature

\begin{tabular}{|c|c|c|c|c|c|c|}
\hline Authors & $\begin{array}{l}\text { Institution } \\
\text { City, Country }\end{array}$ & $\begin{array}{l}\text { Study } \\
\text { Design }\end{array}$ & Interval & $\mathbf{N}$ & $\begin{array}{l}\text { IOP CSF Leak } \\
\text { Rate (\%) }\end{array}$ & $\begin{array}{c}\text { POP CSF } \\
\text { Leak Rate (\%) }\end{array}$ \\
\hline Ajlan et al. (1) & California, USA & Retro & $2007-2012$ & 176 & NA & 4.5 \\
\hline Bokhari et al. (4) & Kogarah, Australia & Retro & $1998-2010$ & 79 & $19 \%$ & 2.5 \\
\hline Boling et al. (5) & Multicentric & Retro & $2002-2014$ & 982 & NA & 5.5 \\
\hline Cerina et al. (12) & Zagreb, Croatia & Pro & $2012-2013$ & 70 & NA & NA \\
\hline Chabot et al. (13) & NY - Illinois, USA & Retro & $2009-2014$ & 39 & 53.8 & 10.3 \\
\hline Chi et al. (14) & Renji, China & Retro & $2011-2012$ & 80 & 20 & 5 \\
\hline Chohan et al. (15) & NY, USA & Retro & 2003-2014 & 62 & 69 & 1.6 \\
\hline Dallapiazza et al. (17) & Virginia, USA & Retro & $2010-2013$ & 56 & 58 & 7.1 \\
\hline Gondim et al. (20) & Fortaleza, Brasil & Retro & 1998-2009 & 301 & 10.3 & 2.6 \\
\hline Gondim et al. (21) & Fortaleza, Brasil & Retro & $2000-2012$ & 374 & NA & 3.7 \\
\hline Hofstetter et al. (24) & NY, USA & Pro & $2004-2010$ & 71 & 60.6 & 1.4 \\
\hline Jakimovski et al. (25) & NY, USA & Retro & 2003-2011 & 203 & 61 & 3.0 \\
\hline Jang et al. (26) & Changwon, South Korea & Retro & 1998-2014 & 331 & 14 & 1.8 \\
\hline Qureshi et al. (32) & Illinois, USA & Retro & 2006-2012 & 78 & 10.3 & 1.3 \\
\hline Robins et al. (35) & Leeds, UK & Retro & $2009-2016$ & 142 & 19.6 & 3.7 \\
\hline Thawani et al. (39) & Pennsylvania, USA & Retro & 2009-2014 & 203 & 40.4 & 10.3 \\
\hline Zhan et al. (42) & Shandong, China & Retro & 2008-2014 & 313 & NA & 3.8 \\
\hline
\end{tabular}

Retro: Retrospective, Pro: Prospective, N: Number of patients, IOP: Intraoperative, POP: Postoperative, CSF: Cerebro-spinal fluid. 


\section{The use of fat and fibrin glue as reconstruction method in a microscopic transsphenoidal approach}

Several reference centres of pituitary pathology do not use a full endoscopic technique (37). It may be explained with two main reasons: 1 ) they do not want to abandon the microscopic technique because of the good outcomes achieved or 2) they are in a transition stage between both techniques and they practice a kind of "assisted endoscopy".

The NSF was designed to be used with the endoscopic technique (31). An easy and correct preparation, following the original work's landmarks, is not achievable with the microscopic technique. Hence, centres that do not use or master the endoscopic technique could not take advantage of NSF during the reconstructive phase. The authors believe that the use of fat and fibrin glue represents a valid alternative for these groups.

NSF is not indicated in standard pituitary surgery. Generally, its application is reserved for the reconstructive phase of extended EEA $(21,33)$. Within the standard approach context, the use of fat and fibrin glue could be considered as an alternative reconstruction method.

When the surgeon, who masters the endoscopic technique, performs a standard approach and there is evidence of intraoperative CSF leak (usually grade 1 or 2), fat and fibrin glue could be used in the reconstructive phase, without performing the NSF.

In the case of an extended EEA, fat and fibrin glue could be used as the only method for intraoperative low-grade CSF leak (grade 1 or 2) or combined with the NSF if the intraoperative CSF leak is of higher entity (grade 3). Cappabianca et al. describe in their series a successful way to combine them through the "3F" technique (11).

Two concepts must be kept in mind in order to make proper use of fat and fibrin glue plus NSF: the different kinds of intraoperative CSF leaks and the indications of extended EEA in pituitary surgery.

In pituitary surgery the indication of extended EEA with the eventual use of NSF is limited to specific cases of pituitary adenomas: dumb-bell shape, supra or para sellar extension (e.g., invasion of III ventricle and encasement of carotid artery), fibrous or rubbery consistency or recurrent tumour $(8,10,27,28)$.

In a recent publication, Cappabianca et al. presented an innovative and useful technique named "3F" (i.e. fat, flap, flash) (11). This technique demonstrates that the fat and fibrin glue could be perfectly combined with the NSF.

The use of fat and fibrin glue proved to be, in our experience, an effective method during the microscopic stage.

Authors believe, according to Cappabianca et al., that it is not useful to be keen on a technique alone (16). Our team is currently undergoing a transition stage and moving to a fully endoscopic technique for pituitary surgery. Some publications demonstrate the efficacy of fat and fibrin glue in the endoscopic era (36) and this reconstruction technique will continue to be performed in our department.

For these reasons, the fat and fibrin glue reconstruction method is far from being an old-fashioned tool; on the contrary, it is part of the vanguard in pituitary surgery.

\section{Limitations}

All patients in this series were treated with a microscopic technique. In the present study, the potential use of this method in the endoscopy field, alone or combined with the NSF technique, is discussed. In order to demonstrate the real clinical application of these conclusions, it is necessary to include patients treated with endoscopic technique. With this intent, our team is working alongside other groups, who masterfully performs the endoscopic technique.

\section{CONCLUSION}

The use of fat and fibrin glue is currently an effective method of treating intraoperative low-grade CSF leak (1 or 2).

It represents an effective anti-CSF leak method that should be considered an essential resource in the skull base neurosurgeon's arsenal of the 21 st century.

Nevertheless, other studies with a more extensive series are needed to validate this hypothesis.

\section{REFERENCES}

1. Ajlan A, Achrol AS, Albakr A, Feroze AH, Westbroek EM, Hwang P, Harsh GR: Cavernous sinus involvement by pituitary adenomas: Clinical implications and outcomes of endoscopic endonasal resection. J Neurol Surg B Skull Base 78:273-282, 2017

2. Basso A, Campero A, Previgliano I: Cirurgía de los tumores hipofisarios. In: Editores SG (ed), Hipófisis. Fisiopatología. Buenos Aires, 2004:389-402

3. Basso A, Gonzales-Abbati S, Campero A: Tratamiento quirúrgico de los adenomas de la hipófisis. In: Científicos RCLMy (ed), Neurocirugía. Aspectos Clínicos y Quirúrgicos. Buenos Aires, 2010:396-401

4. Bokhari AR, Davies MA, Diamond T: Endoscopic transsphenoidal pituitary surgery: A single surgeon experience and the learning curve. Br J Neurosurg 27:44-49, 2013

5. Boling CC, Karnezis TT, Baker AB, Lawrence LA, Soler ZM, Vandergrift WA, Wise SK, Del Gaudio JM, Patel ZM, Rereddy SK, Lee JM, Khan MN, Govindaraj S, Chan C, Oue S, Psaltis AJ, Wormald PJ, Trosman S, Stokken J, Woodard T, Sindwani R, Schlosser RJ: Multi-institutional study of risk factors for perioperative morbidity following transnasal endoscopic pituitary adenoma surgery. Int Forum Allergy Rhinol 6:101107, 2016

6. Campero A, Socolovsky M, Torino R, Martins C, Yasuda A, Rhoton AL: Anatomical landmarks for positioning the head in preparation for the transsphenoidal approach: The sphenosellar point. Br J Neurosurg 23:282-286, 2009 
7. Campero A, Villalonga JF, Basso A: Anatomical risk factors for intraoperative cerebrospinal fluid leaks during transsphenoidal surgery for pituitary adenomas. World Neurosurg S18788750(18):32917-32916, 2019

8. Cappabianca P, Alfieri A, Colao A, Cavallo LM, Fusco M, Peca C, Lombardi G, de Divitiis E: Endoscopic endonasal transsphenoidal surgery in recurrent and residual pituitary adenomas: Technical note. Minim Invasive Neurosurg 43:3843, 2000

9. Cappabianca P, Di Somma A, de Notaris M: Rerum magistra experientia est: The evolution of modern endoscopic endonasal skull base surgery and reconstruction techniques. World Neurosurg 82:e67-69, 2014

10. Cappelletti M, Ruggeri AG, Spizzichino L, D'Amico A, D'avella E, Delfini R: Fibrous pituitary macroadenomas: Predictive role of preoperative radiologic investigations for proper surgical planning in a cohort of 66 patients. World Neurosurg 121:e449-e457, 2019

11. Cavallo LM, Solari D, Somma T, Cappabianca P: The $3 f$ (fat, flap \& flash) technique for skull base reconstruction after endoscopic endonasal suprasellar approach. World Neurosurg 126:439-446, 2019

12. Cerina V, Kruljac I, Radosevic JM, Kirigin LS, Stipic D, Pecina HI, Vrkljan M: Diagnostic accuracy of perioperative measurement of basal anterior pituitary and target gland hormones in predicting adrenal insufficiency after pituitary surgery. Medicine (Baltimore) 95:e2898, 2016

13. Chabot JD, Chakraborty S, Imbarrato G, Dehdashti AR: Evaluation of outcomes after endoscopic endonasal surgery for large and giant pituitary macroadenoma: A retrospective review of 39 consecutive patients. World Neurosurg 84:978988, 2015

14. Chi F, Wang Y, Lin Y, Ge J, Qiu Y, Guo L: A learning curve of endoscopic transsphenoidal surgery for pituitary adenoma. J Craniofac Surg 24:2064-2067, 2013

15. Chohan MO, Levin AM, Singh R, Zhou Z, Green CL, Kazam JJ, Tsiouris AJ, Anand VK, Schwartz TH: Three-dimensional volumetric measurements in defining endoscope-guided giant adenoma surgery outcomes. Pituitary 19:311-321, 2016

16. Conger A, Zhao F, Wang X, Eisenberg A, Griffiths C, Esposito F, Carrau RL, Barkhoudarian G, Kelly DF: Evolution of the graded repair of CSF leaks and skull base defects in endonasal endoscopic tumor surgery: Trends in repair failure and meningitis rates in 509 patients. J Neurosurg 130:861875,2018

17. Dallapiazza R, Bond AE, Grober Y, Louis RG, Payne SC, Oldfield EH, Jane JA: Retrospective analysis of a concurrent series of microscopic versus endoscopic transsphenoidal surgeries for Knosp Grades 0-2 nonfunctioning pituitary macroadenomas at a single institution. J Neurosurg 121:511517, 2014

18. Daly AF, Rixhon M, Adam C, Dempegioti A, Tichomirowa MA, Beckers A: High prevalence of pituitary adenomas: A cross-sectional study in the province of Liege, Belgium. J Clin Endocrinol Metab 91:4769-4775, 2006

19. Esposito F, Dusick JR, Fatemi N, Kelly DF: Graded repair of cranial base defects and cerebrospinal fluid leaks in transsphenoidal surgery. Oper Neurosurg (Hagerstown) 60:295-303; discussion 303-294, 2007
20. Gondim JA, Almeida JP, Albuquerque LA, Schops M, Gomes E, Ferraz T, Sobreira W, Kretzmann MT: Endoscopic endonasal approach for pituitary adenoma: Surgical complications in 301 patients. Pituitary 14:174-183, 2011

21. Gondim JA, Almeida JP, de Albuquerque LA, Gomes E, Schops M, Mota JI: Endoscopic endonasal transsphenoidal surgery in elderly patients with pituitary adenomas. J Neurosurg 123:3138, 2015

22. Griffiths CF, Barkhoudarian G, Cutler A, Duong HT, Karimi K, Doyle O, Carrau R, Kelly DF: Analysis of olfaction after bilateral nasoseptal rescue flap transsphenoidal approach with olfactory mucosal preservation. Otolaryngol Head Neck Surg 161(5):881-889, 2019

23. Hadad G, Bassagasteguy L, Carrau RL, Mataza JC, Kassam A, Snyderman $\mathrm{CH}$, Mintz A: A novel reconstructive technique after endoscopic expanded endonasal approaches: Vascular pedicle nasoseptal flap. Laryngoscope 116:1882-1886, 2006

24. Hofstetter CP, Nanaszko MJ, Mubita LL, Tsiouris J, Anand VK, Schwartz TH: Volumetric classification of pituitary macroadenomas predicts outcome and morbidity following endoscopic endonasal transsphenoidal surgery. Pituitary 15:450-463, 2012

25. Jakimovski D, Bonci G, Attia M, Shao H, Hofstetter C, Tsiouris AJ, Anand VK, Schwartz TH: Incidence and significance of intraoperative cerebrospinal fluid leak in endoscopic pituitary surgery using intrathecal fluorescein. World Neurosurg 82:e513-523, 2014

26. Jang JH, Kim KH, Lee YM, Kim JS, Kim YZ: Surgical results of pure endoscopic endonasal transsphenoidal surgery for 331 pituitary adenomas: A 15-year experience from a single institution. World Neurosurg 96:545-555, 2016

27. Kassam A, Snyderman CH, Mintz A, Gardner P, Carrau RL: Expanded endonasal approach: The rostrocaudal axis. Part I. Crista galli to the sella turcica. Neurosurg Focus 19(1):E3, 2005

28. Kassam A, Snyderman CH, Mintz A, Gardner P, Carrau RL: Expanded endonasal approach: The rostrocaudal axis. Part II. Posterior clinoids to the foramen magnum. Neurosurg Focus 19(1):E4, 2005

29. Kassam AB, Thomas A, Carrau RL, Snyderman CH, Vescan A, Prevedello D, Mintz A, Gardner P: Endoscopic reconstruction of the cranial base using a pedicled nasoseptal flap. Neurosurgery 63(1 Suppl 1):ONS44-ONS53, 2008

30. Little AS, Kelly DF, White WL, Gardner PA, FernandezMiranda JC, Chicoine MR, Barkhoudarian G, Chandler JP, Prevedello DM, Liebelt BD, Sfondouris J, Mayberg MR, Group TS: Results of a prospective multicenter controlled study comparing surgical outcomes of microscopic versus fully endoscopic transsphenoidal surgery for nonfunctioning pituitary adenomas: The Transsphenoidal Extent of Resection (TRANSSPHER) Study. J Neurosurg 132(4):1043-1053, 2019

31. Patel MR, Stadler ME, Snyderman CH, Carrau RL, Kassam AB, Germanwala AV, Gardner P, Zanation AM: How to choose? Endoscopic skull base reconstructive options and limitations. Skull Base 20:397-404, 2010

32. Qureshi T, Chaus F, Fogg L, Dasgupta M, Straus D, Byrne RW: Learning curve for the transsphenoidal endoscopic endonasal approach to pituitary tumors. Br J Neurosurg 30:637-642, 2016 
33. Reuter G, Bouchain O, Demanez L, Scholtes F, Martin D: Skull base reconstruction with pedicled nasoseptal flap: Technique, indications, and limitations. J Craniomaxillofac Surg 47:29-32, 2019

34. Riley CA, Tabaee A, Conley L, Amine M, Soneru CP, Anand VK, Schwartz TH: Long-term sinonasal outcomes after endoscopic skull base surgery with nasoseptal flap reconstruction. Laryngoscope 129:1035-1040, 2019

35. Robins JMW, Alavi SA, Tyagi AK, Nix PA, Wilson TM, Phillips NI: The learning curve for endoscopic trans-sphenoidal resection of pituitary macroadenomas. A single institution experience, Leeds, UK. Acta Neurochir (Wien) 160:39-47, 2018

36. Roca E, Penn DL, Safain MG, Burke WT, Castlen JP, Laws ER: Abdominal fat graft for sellar reconstruction: Retrospective outcomes review and technical note. Oper Neurosurg (Hagerstown) 16:667-674, 2019

37. Solari D, Zenga F, Angileri FF, Barbanera A, Berlucchi S, Bernucci C, Carapella C, Catapano D, Catapano G, Cavallo LM, D’Arrigo C, de Angelis M, Denaro L, Desogus N, Ferroli P, Fontanella MM, Galzio RJ, Gianfreda CD, lacoangeli M, Lauretti L, Locatelli D, Locatelli M, Luglietto D, Mazzatenta D, Menniti A, Milani D, Nasi MT, Romano A, Ruggeri AG, Saladino A, Santonocito O, Schwarz A, Skrap M, Stefini R, Volpin L, Wembagher GC, Zoia C, Zona G, Cappabianca P: A survey on pituitary surgery in Italy. World Neurosurg 123:e440-e449, 2019
38. Strickland BA, Lucas J, Harris B, Kulubya E, Bakhsheshian J, Liu C, Wrobel B, Carmichael JD, Weiss M, Zada G: Identification and repair of intraoperative cerebrospinal fluid leaks in endonasal transsphenoidal pituitary surgery: Surgical experience in a series of 1002 patients. J Neurosurg 129:425429, 2018

39. Thawani JP, Ramayya AG, Pisapia JM, Abdullah KG, Lee JY, Grady MS: Operative strategies to minimize complications following resection of pituitary macroadenomas. J Neurol Surg B Skull Base 78:184-190, 2017

40. Villalonga JF, Centeno TR, Sáenz A, Solari D, Cervio A, Campero A: The mixed sellar barrier: A new subtype of this novel concept. World Neurosurg 132:e5-e13, 2019

41. Villalonga JF, Pilonieta M, Revuelta Barbero JM, Carrau RL, Prevedello DM: Pituitary adenoma concomitant with chiari I malformation: Case report and literature review. World Neurosurg 129:45-48, 2019

42. Zhan R, Ma Z, Wang D, Li X: Pure endoscopic endonasal transsphenoidal approach for nonfunctioning pituitary adenomas in the elderly: Surgical outcomes and complications in 158 patients. World Neurosurg 84:1572-1578, 2015

43. Zwagerman NT, Wang EW, Shin SS, Chang YF, FernandezMiranda JC, Snyderman CH, Gardner PA: Does lumbar drainage reduce postoperative cerebrospinal fluid leak after endoscopic endonasal skull base surgery? A prospective, randomized controlled trial. J Neurosurg 1-7, 2018 (Online ahead of print) 